\title{
Anther Culture and Plant Regeneration of Tetraploid Purple Coneflower (Echinacea purpurea L.)
}

\author{
Xiaolu Chen 1,2, Dahanayake Nilanthi ${ }^{2,3}$, Yuesheng Yang2 ${ }^{2}$, Hong $\mathrm{Wu}^{2}$ \\ ${ }^{1}$ Tropical Crops Genetic Resources Institute, Chinese Academy of Tropical Agricultural Sciences/Key Laboratory of Crop Gene \\ Resources and Germplasm Enhancement in Southern China, Ministry of Agriculture, Danzhou, China \\ ${ }^{2}$ College of Life Science, South China Agricultural University, Guangzhou, Guangdong, China \\ ${ }^{3}$ Department of Agricultural Biology, Faculty of Agriculture, University of Ruhuna, Matara, Sri Lanka \\ Email: *ysyang@scau.edu.cn
}

How to cite this paper: Chen, X.L., Nilanthi, D., Yang, Y.S. and Wu, H. (2016) Anther Culture and Plant Regeneration of Tetraploid Purple Coneflower (Echinacea purpurea L.). Journal of Biosciences and Medicines, 4, 89-96.

http://dx.doi.org/10.4236/jbm.2016.412013

Received: November 10, 2016 Accepted: December 1, 2016

Published: December 8, 2016

\begin{abstract}
Anthersisolated from tetraploid purple coneflowerplants were cultured in vitro. The highest callus induction rate was obtained when the medium was consisted of N6 basal elements, $4 \%$ sucrose, $0.5 \mathrm{mg} \cdot \mathrm{L}^{-1} \mathrm{BA}$, and $0.10 \mathrm{mg} \cdot \mathrm{L}^{-1} \mathrm{NAA}$. Various morphogenesis such as globular, heart-shape, torpedo-shapeand final state embryos as well asvarious texture calluses around were observed. Out of 110 plantlets regenerated, 104 were confirmed as diploid and the rest were as tetraploid. Plants of one diploid offspring strain presented aspecialcharacter in pot: unlike the original tetraploid plants, it grown tubular, bisexual ray florets. The results obtained in the present studies indicated that although the tetraploid purple coneflower plants produced only diploid microspores, the recovery of some useful mutants through in vitro anther cultures might be reasonably expected.
\end{abstract}

\section{Keywords}

Purple Coneflower, Echinacea purpurea, Anther Culture; Tetraploid

\section{Introduction}

As a medicinal plant with functional compounds accumulated in the vegetative parts [1], polyploidization has been carried out successfully [2] [3] [4], and has been proved a breeding strategy worth tryingforpurple coneflower [5] [6] [7]. As anther culture has been reported in purple coneflower which resulted in the regeneration of haploid plants [8], it is foreseeable that aneuploidy plants may occurthrough culturing anthers isolated from the multiploid plants. Aneuploidy triticale has been obtained from regenerants in 
in vitro anther cultures [9]. Wild purple coneflower plants are diploids [10], and tetraploid purple coneflower plantsrecovered from colchicine-treated diploid explants have been proved with high value because they contain higher concentrations of cichoric acid than the natural diploid plants do [11]. Asabnormal chromosome behaviors have been found in tetraploid purple coneflower plants after the first meiotic diplotene and after the second meiotic telophase, the present study is to certify if aneuploidy could be induced through culturing anthers from tetraploid purple coneflower plants.

\section{Materials and Methods}

\subsection{Materials}

Original diploid purple coneflower plants were grown from seeds provided by the Company of Plantation Products (Norton, MA, USA). Tetraploid plants were obtained by in vitro treatment of diploid explants with colchicine, and plant regeneration was induced in these colchicine-treated explants [4]. The tetraploid plants were transplanted to pots with soil.

\subsection{Methods}

\subsubsection{Observation on Morphological Change of Florets and Microspores}

A capitulum in which the first few florets were open was cut from the inflorescence stem. Florets with different sizes were picked up and the photos were taken in sequence. Each picked floret was placed on a glass slide. Pelea, perianth and pistil were removed with a tweezers. The anthers were cut into pieces with a blade. The pollen mother cells or microspores were squeezed out of the anther wall. The slides with cells were stained with Carbol fuchsin, observed under an optical microscope, and photos were taken.

\subsubsection{Accessing Microspore Develop Process and Determining the Callus Induced Rate}

A capitulum in which the first few florets were open was cut from the inflorescence stem. Thecapitulum was surface-sterilized by immersingin $70 \%$ ethanol for 1 minute, soaking in a $0.1 \%$ mercuricchloride solution for 10 minutes and followed by $1 \%$ sodiumhypochlorite solution containing one drop of Tween 20 per50 mL for 10 minutes. The surface-sterilizedcapitulumwasrinsed three times in sterile deionized water. Each floret was pulled out and the pelea, perianth, and pistil were removed. Each 20 anthers were inoculated onto medium in one bottle. Each jar was filled with $40 \mathrm{~mL}$ of medium and covered with a polycarbonate screw cap. The medium was consisted of N6 basal elements, $5 \%$ sucrose, $0.5 \mathrm{mg} \cdot \mathrm{L}^{-1} \mathrm{BA}$, and $0.10 \mathrm{mg} \cdot \mathrm{L}^{-1} \mathrm{NAA}$. The cultures were kept in light conditions with a 12-hour photoperiod under cool-white light (about $50 \mu \mathrm{mol}$ $\mathrm{m}^{-2} \cdot \mathrm{s}^{-1}$ ), and all thecultures were kept in a room with temperature of $25^{\circ} \mathrm{C}-27^{\circ} \mathrm{C}$. Numbers of callus were counted 30 days after initiation of the cultures.

\subsubsection{Investigation of the Effect of Genotype on Callus Induction}

Anthers isolated from plants with different genotypes were cultured under same condi- 
tions according to the reported methods [8]. Numbers of callus were counted 30 days after initiation of the cultures.

\subsubsection{Investigation of the Effect of Basic Medium on Callus Induction}

The surface-sterilized anthers were prepared by the same way given in 2.2.2 and then inoculated onto medium with $5 \%$ sucrose, $0.5 \mathrm{mg} \cdot \mathrm{L}^{-1} \mathrm{BA}, 0.10 \mathrm{mg} \cdot \mathrm{L}^{-1} \mathrm{NAA}$, and four groups of different basal elements, N6, C17, W14, and Potato II. Numbers of callus were counted 30 days after initiation of the cultures.

\subsubsection{Investigation of the Effect of Sucrose Concentration on Callus Induction Rate}

The surface-sterilized anther was prepared by the same way given in 2.2.2 and then inoculated onto medium consists $\mathrm{N} 6$ basal elements, $0.5 \mathrm{mg} \cdot \mathrm{L}^{-1} \mathrm{BA}$, and $0.10 \mathrm{mg} \cdot \mathrm{L}^{-1}$ NAA, and different concentration of sucrose, $4 \%, 5 \%, 6 \%$, and $7 \%$ respectively. Numbers of callus were counted 30 days after initiation of the cultures.

\subsubsection{Induction of Adventitious Buds and Roots, and Counting of the Chromosome Number}

Induction of adventitious buds and roots, and counting of the chromosome were performed by the reported methods [8].

\subsubsection{Data Collection and Analysis}

Callus induction rate (\%) was calculated by dividing the No. of callus with the No. of anthers cultured. Statistical analysis of the data was carried out with ANOVA analyses using the SPSS 19.0 software, and the significant differences among the means were determined by the Duncan's multiple range tests for more than two data sets, or by the independent sample $t$-test for two sets of data. The differences were considered significant when the $P$ values were less than 0.05 .

\section{Results}

\subsection{Relationship between Morphological Change of Florets and Microspores}

As showed in Figure 1, the color of floret was closely related with the stage of microspore.

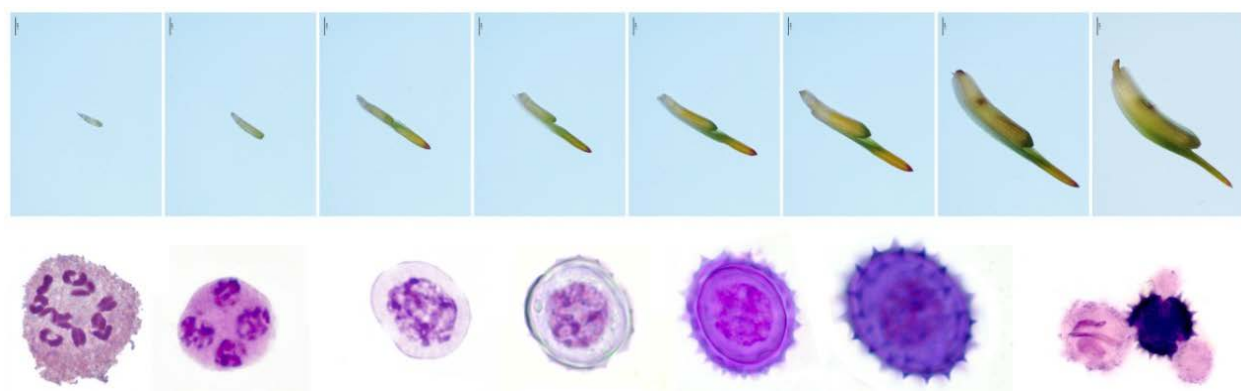

Figure 1. Relationship between morphological change of florets and microspores. From left to right: meiosis phase, tetrad, early uninucleate, early-middle uninucleate, middle uninucleate, late uninucleate, mature pollen; Bar $=1 \mathrm{~mm}$. 
The appearing of yellow color was almost simultaneous with the formation of pollen wall. The pollens in brown color floret were mature. A maturemicrosporeconsists of one vegetative nucleus and two generative nucleuses.

\subsection{Relation between Microspore Development Process and Callus Induced}

The callus induction rate was connected directly to the development state of microspores. Microspores from early uninucleate phase to late uninucleatephase represented a high potential in callus induction rate (Table 1 ).

\subsection{Effect of Genotype on Callus Induction}

Callus induction rate of anthers isolated from plants with different genotype were evidently different from each other (Table 2).

\subsection{Effect of Basic Medium on Callus Induction}

Basal medium elementary affected the callus induction rate strongly. Callus induction rates for C17, W14, and Potato II basal elements were significantly lower than that for the control (Table 3).

\subsection{Effect of Sucrose on Callus Induction}

Callus induction rate on medium with $4 \%, 5 \%, 6 \%$ and $7 \%$ sucrose were not significant

Table 1. Relation between microspore development state and callus induction rate.

\begin{tabular}{cccc}
\hline $\begin{array}{c}\text { Length of floret } \\
(\mathrm{mm})\end{array}$ & Color of floret & State of microspore & Callus induction rate (\%) \\
\hline$>6.0$ & Brown & Mature pollen & $1.25 \pm 1.25 \mathrm{e}^{*}$ \\
$5.9-6.0$ & Deep yellow & Mature pollen & $33.75 \pm 6.57 \mathrm{~d}$ \\
$3.8-5.9$ & Yellow & Mature pollen & $45.00 \pm 2.04 \mathrm{c}$ \\
$2.6-3.8$ & Faint yellow & Late uninucleate & $83.75 \pm 5.15 \mathrm{~b}$ \\
$1.8-2.6$ & Faint yellow & Middleuninucleate, late & $96.25 \pm 1.25 \mathrm{a}$ \\
$1.2-1.8$ & Colorless or pale green & uninucleate & \\
$0.8-1.2$ & Colorless or pale green & Early-middle uninucleate & $96.67 \pm 1.67 \mathrm{a}$ \\
$0.6-0.8$ & Colorless or pale green & Early uninucleate & $96.25 \pm 2.39 \mathrm{a}$ \\
\hline
\end{tabular}

${ }^{*}$ Data in the same column followed by different letters are significantly different by Duncan's test at $P<0.05$ level.

Table 2. Effect of genotype on callus induction rate.

\begin{tabular}{cccc}
\hline Genotypecode & No. of anther & No. of callus & Callus induction rate (\%) \\
\hline T1 & 580 & 77 & 13.28 \\
T2 & 480 & 119 & 24.79 \\
T3 & 160 & 77 & 44.38 \\
T4 & 640 & 143 & 22.34 \\
\hline
\end{tabular}


different, while the highest induction rate was obtained when the concentration of sucrose was of $4 \%$ (Table 4 ).

\subsection{Observation of Cultivation}

Some anthers did not yield callus and died on callus induction medium, some anthers recovered hyperhydricitycallus and/or adventitious buds, and some produced healthy shoots which initiated roots afterward (Figure 2). Moreover, some calluses did not regenerate plants, but formed on the surface numerous globularembryos, heart-shapeembryos, torpedo-shape embryos (Figure 3). Among the 110 plantlets investigated,

Table 3. Effect of basic medium on callus induction rate.

\begin{tabular}{cc}
\hline Basic medium & Callus inductionrate (\%) \\
\hline N6 (CK) & $65.00 \pm 6.21 \mathrm{a}^{*}$ \\
C17 & $31.67 \pm 6.06 \mathrm{~b}$ \\
W14 & $32.50 \pm 7.50 \mathrm{~b}$ \\
Potato II & $41.25 \pm 5.54 \mathrm{~b}$ \\
\hline
\end{tabular}

${ }^{*}$ Data in the same column followed by different letters are significantly different by Duncan's test at $P<0.05$ level.

Table 4. Effect of sucrose on callus induction rate.

\begin{tabular}{cc}
\hline Sucrose concentration (\%) & Callus inductionrate (\%) \\
\hline 4.0 & $70.00 \pm 13.53 \mathrm{a}^{\star}$ \\
5.0 & $68.75 \pm 12.81 \mathrm{a}$ \\
6.0 & $66.43 \pm 14.99 \mathrm{a}$ \\
7.0 & $66.88 \pm 13.59 \mathrm{a}$ \\
\hline
\end{tabular}

${ }^{*}$ Data in the same column followed by different letters are significantly different by Duncan's test at $P<0.05$ level.

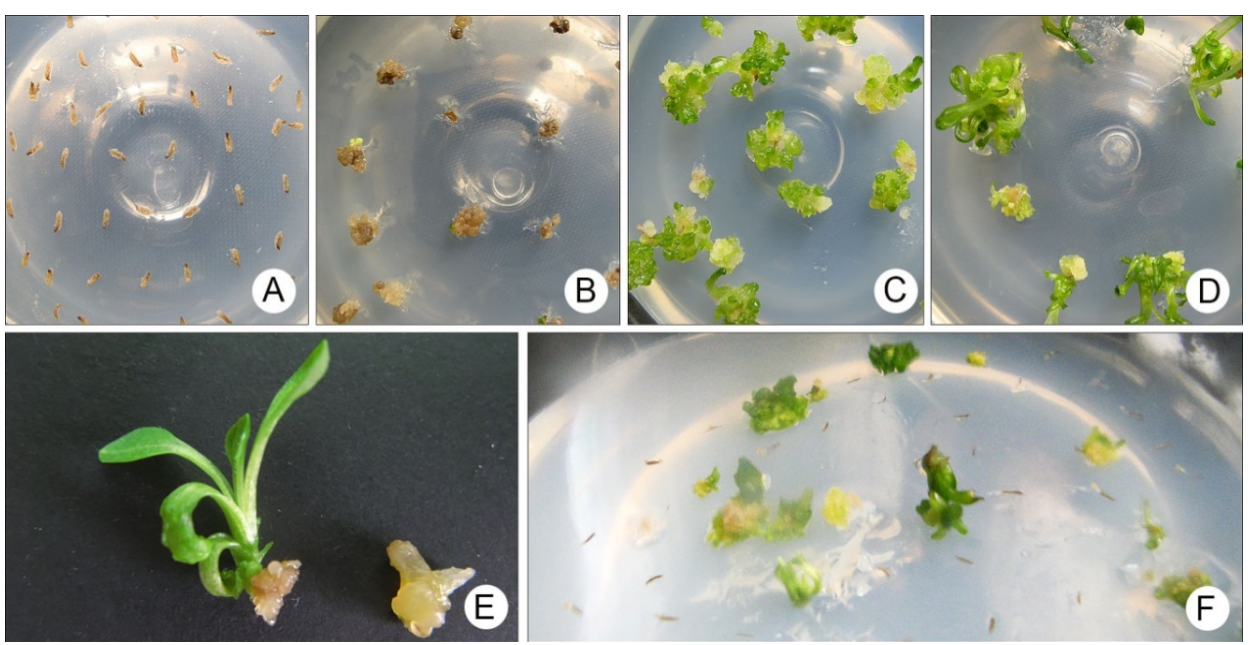

Figure 2. Responses of anthers cultured on callus induction medium. (A): inoculated anthers; (B): browning callus; (C): shoot-buds induced from callus; (D): adventitious buds induced from callus; (E): a normal regenerated bud induced from a piece of callus; (F): embryoids and shoots induced directly from tetraploid anthers. 
six were confirmed as tetraploid and the rest were diploid. None of aneuploid was detected in present study. One abnormal phenotype (diploid) was detected. It grew tubular, bisexual ray florets (Figure 4).

\section{Discussion and Conclusions}

The development of microspores was related to appearance of floret in many plants, for instance, triticale (XTriticosecale Wittmack) [9]. The present study revealed that the microspores may be suitable for inducing callus when the floret was faint yellow, colorless, or pale green. The appearing of color on florets and the microspores develop process were linked to the callus induction rates. Large variation in the callus induction rates was observed among the four genotypes. These results coincide with those reported in literatures [8] [12].

In comparison to C17, W14, and Potato II, N6 was more suitable for culturing anther from tetraploid purple coneflower plants. Concentration of sucrose, from $4 \%$ to $6 \%$, seems influenced the culture non-significantly. The callus, which induced from tetraploid anthers, seems weaker compared to those from diploid anthers [8]. Some advent-
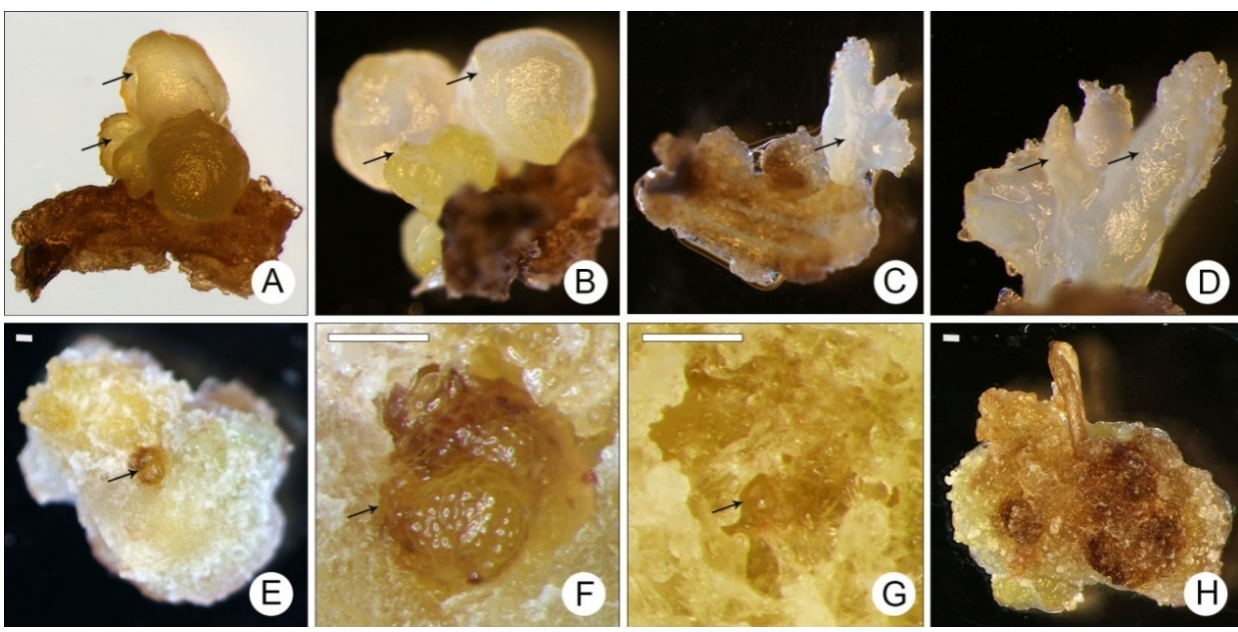

Figure 3. Morphogenesisof callus induced from anthers. (A) globularembryo; (B) heart-shapeembryo; (C) and (D), torpedo-shape; $(\mathrm{E})-(\mathrm{G})$ : embryo and callus around; $\mathrm{H}$ : callus, bar $=200$ $\mu \mathrm{m}$.
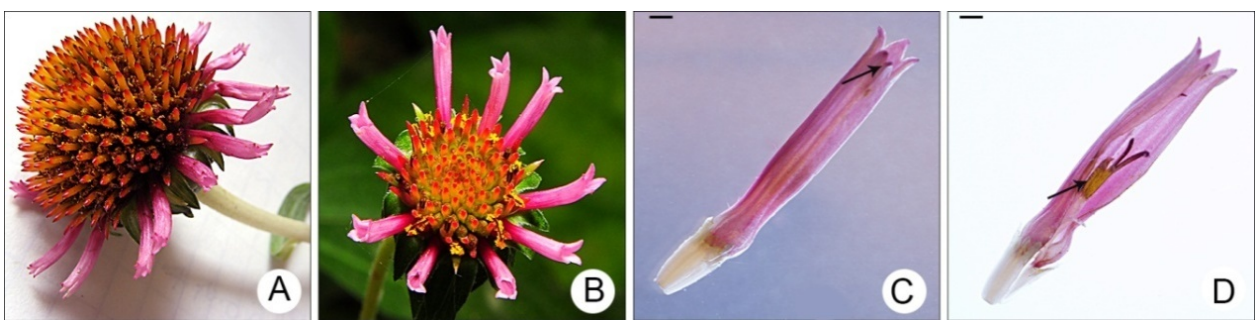

Figure 4. An inflorescence andits floret of adiploid regenerant recovered from tetraploid plant anther cultures. (A) inflorescence in 2012; (B) inflorescence in 2013; (C) a tubular ray floret, arrow shows top end of the floret which doesn't cracks to ovary like others; (D) inner sight of a tubular ray floret, arrow shows pistil and stamens. Bar $=1 \mathrm{~mm}$. 
tious buds regenerated from the callus were hyperhydric, failed to develop roots and died finally. As a result the counting of chromosome number did not perform on this group of buds. Some newly reported strategies may help solve this problem [13].

Out of 110 plantlets regenerated in the cultures were investigated. Among them 104 were diploid and the rest were tetraploid. This result proved that most of the plantlets were androgenic progeny, rather than adventitious buds of somatic cells, such asanther wall cells. The abnormal phenotype, which grown tubular, bisexual ray florets, indicated that though the tetraploid purple coneflower plants produced diploid microspore, the recovery of some useful mutants through in vitro anther cultures might be reasonably expected.

In conclusion, the present study implicated that the meiosis process in tetraploid purple coneflower plants was quite orderlysince so far there have been no aneuploid recovered. For this reason it might be considered that the reductional division of chromosomes in purple coneflower is not controlled by base complementation pairing rule only but also by genes [14] [15].

\section{Acknowledgements}

This study was funded by the Scientific and Technological Program of Guizhou province (\#2013-6011), and the Science and technology cooperation projects of Hainan Province, China (\#KJHZ2015-15).

\section{Conflicts of Interest}

The authors declare no conflict of interest.

\section{References}

[1] Bauer, R. (1999) Chemistry, Analysis and Immunological Investigations of Echinacea Phytopharmaceuticals. In: Wagner, H., Ed., Immunomodulatory Agents from Plants, Birkhäuser Basel, Basel, 41-88. https://doi.org/10.1007/978-3-0348-8763-2_2

[2] Abdoli, M., Moieni, A. and Badi, H.N. (2013) Morphological, Physiological, Cytological and Phytochemical Studies in Diploid and Colchicine-Induced Tetraploid Plants of Echinacea purpurea (L.). Acta Physiologiae Plantarum, 35, 2075-2083.

https://doi.org/10.1007/s11738-013-1242-9

[3] Nilanthi, D. and Yang, Y. (2013) In Vitro Induction of Octaploid from Colchicine-Treated Tetraploid Petiole Explants of Purple Coneflower (Echinacea purpurea L.). Tropical Agricultural Research and Extension, 16.

[4] Nilanthi, D., Chen, X., Zhao, F., Yang, Y. and Wu, H. (2009) Induction of Tetraploids from Petiole Explants through Colchicine Treatments in Echinacea purpurea L. J Biomed Biotechnol, 2009, Article ID: 343485. https://doi.org/10.1155/2009/343485

[5] Chen, R., Jiang, W.Z., Li, Q.L., Li, X.L., Chen, X.L., Yang, Y.S., et al. (2015) Comparison of Seven Colchicine-Induced Tetraploid Clones with Their Original Diploid Clones in Purple Coneflower (Echinacea purpurea L.). Euphytica, 1-13.

[6] Chen, X.L., Chen, R., Li, Q.L., Yang, Y.S. and Wu, H. (2014) Cytological Comparison of Diploid, Triploid, Tetraploid and Hexaploid in Purple Coneflower (Echinacea purpurea L.). Proceedings of 2013 International Conference on Biological, Medical and Chemical Engi- 
neering (BMCE2013), Hong Kong, DEStech Publications, Inc., 212.

[7] Chen, X.L., Zhang, J.J., Chen, R., Li, Q.L., Yang, Y.S. and Wu, H. (2014) Comparison among Diploid, Its Colchicine-Induced Tetraploid and Their Crossed Descendent Triploid in Purple Coneflower (Echinacea purpurea L.). International Conference on Biological Engineering and Biomedical (BEAB2014), Yichang, DEStech Publications, Inc.

[8] Zhao, F.C., Nilanthi, D., Yang, Y.S. and Wu, H. (2006) Anther Culture and Haploid Plant Regeneration in Purple Coneflower (Echinacea purpurea L.). Plant Cell, Tissue and Organ Culture, 86, 55-62. https://doi.org/10.1007/s11240-006-9096-0

[9] Oleszczuk, S., Rabiza-Swider, J., Zimny, J. and Lukaszewski, A.J. (2011) Aneuploidy among Androgenic Progeny of Hexaploid Triticale (XTriticosecale Wittmack). Plant Cell Rep, 30, 575-586. https://doi.org/10.1007/s00299-010-0971-0

[10] McGregor, R.L. (1968) The Taxonomy of the Genus Echinacea (Compositae). University of Kansas.

[11] Xu, C.G., Tang, T.X., Chen, R., Liang, C.H., Liu, X.Y., Wu, C.L., et al. (2014) A Comparative Study of Bioactive Secondary Metabolite Production in Diploid and Tetraploid Echinacea purpurea (L.) Moench. Plant Cell, Tissue and Organ Culture, 116, 323-332. https://doi.org/10.1007/s11240-013-0406-Z

[12] Li, Q., Chen, R., Chen, X., Yang, Y. and Wu, H. (2013) Estimation of the Cloning Potential in Six Selected Genotypes of Purple Coneflower. Biotechnol Biotec Eq, 27, 3911-3917. https://doi.org/10.5504/BBEQ.2013.0057

[13] Chen, R., Jin, Y.H., Li, Q.L., Chen, X.L., Yang, Y.S. and Wu, H. (2013) Some Effective Methods for Dealing with the Problem of Hyperhydricity in Cloning Purple Coneflower. International Conference on Biological, Medical and Chemical Engineering (BMCE2013), Hong Kong.

[14] Griffiths, S., Sharp, R., Foote, T.N., Bertin, I., Wanous, M., Reader, S., et al. (2006) Molecular Characterization of $\mathrm{Ph} 1$ as a Major Chromosome Pairing Locus in Polyploid Wheat. Nature, 439, 749-752. https://doi.org/10.1038/nature04434

[15] Gill, K.S., Gill, B.S., Endo, T.R. and Mukai, Y. (1993) Fine Physical Mapping of Ph1, a Chromosome Pairing Regulator Gene in Polyploid Wheat. Genetics, 134, 1231-1236.

Submit or recommend next manuscript to SCIRP and we will provide best service for you:

Accepting pre-submission inquiries through Email, Facebook, LinkedIn, Twitter, etc. A wide selection of journals (inclusive of 9 subjects, more than 200 journals)

Providing 24-hour high-quality service

User-friendly online submission system

Fair and swift peer-review system

Efficient typesetting and proofreading procedure

Display of the result of downloads and visits, as well as the number of cited articles Maximum dissemination of your research work

Submit your manuscript at: http://papersubmission.scirp.org/

Or contact jbm@scirp.org 